\title{
AS METÁFORAS DO FUTEBOL BRASILEIRO
}

Deize Crespim Pereira*

RESUMO: Este estudo constitui uma análise qualitativa das expressões metafóricas encontradas no domínio do futebol brasileiro. O corpus se constitui de 316 ocorrências coletadas da fala de locutores brasileiros, que transmitiram jogos de futebol pela televisão ou pelo rádio, no ano de 2005. Utilizando os pressupostos da linguí́stica funcional e da linguística cognitiva, proponho-me a mostrar como utilizamos domínios concretos e familiares de nossa experiência para conceptualizar o futebol. O trabalho comprova a existência de motivações icônicas, não-arbitrárias, que subjazem as expressões metafóricas.

PALAVRAS-CHAVE: Metáforas; Português Brasileiro; Linguiística Funcional; Linguiística Cognitiva.

\section{INTRODUÇÃO}

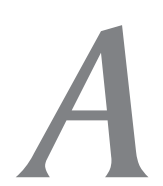

motivação deste estudo provém da leitura do livro Metaphors we live by de Lakoff \& Johnson (1980). A observação desses autores de que as metáforas permeiam não só nossa linguagem, mas também nossa conceptualização do mundo, nossos pensamentos e ações, levou-me a refletir sobre o uso da linguagem figurada no cotidiano.

Como acompanho sempre a transmissão de jogos de futebol pela televisão e pelo rádio, chamou-me logo a atenção a alta frequiência de utilização de metáforas nesse domínio.

Utilizando os pressupostos da Semântica Cognitiva e da Linguiística Funcional, proponho-me, neste trabalho, a analisar as metáforas encontradas em um corpus constituído de 316 ocorrências

Universidade de São Paulo. 
PEREIRA, Deize Crespim. As metáforas do futebol brasileiro.

retiradas da fala de locutores brasileiros, que transmitiram jogos de futebol pela televisão e pelo rádio, ao longo do ano de $2005 .{ }^{1}$

A adoção desse objeto de análise, em um estudo sobre semântica, justifica-se na medida em que consideramos a capital importância do futebol na sociedade brasileira. Trata-se de um esporte popular de massa, que atinge todas as classes, constitui um símbolo da identidade nacional e exerce um papel fundamental na nossa visão e conceptualização da nação brasileira.

\footnotetext{
O futebol, gradualmente, se tornou um dos instrumentos brasileiros de pensar e de, sobretudo, classificar o mundo. A nação brasileira não é só metaforizada no futebol, ela passa a "existir" como algo concreto e palpável por meio das imagens constituídas a partir desse esporte. O futebol é um discurso capital sobre a nacionalidade. Não é simplesmente um outro discurso sobre a brasilidade, mas fundamental para sua constituição. Não há dúvida de que o futebol é um mapa alternativo, mas é um mapa tão real quanto aquele da vida econômica ou política, pois possibilita o sentimento da nação. (Machado, 2005)

Só não podemos nos esquecer de que o futebol é uma caricatura, no sentido de que traz em si os traços essenciais da sociedade brasileira. (Proni, 2005)
}

O trabalho está dividido em cinco partes. No item 2, exponho os pressupostos teóricos e metodológicos que nortearam a análise dos dados, a qual é apresentada no item 3. O item 4 traz as considerações finais. E o item 5, por fim, contém as referências bibliográficas.

\section{PRESSUPOSTOS TEÓRICOS E METODOLÓGICOS}

Os pressupostos teóricos e metodológicos deste trabalho foram retirados das obras de Lakoff \& Johnson (1980) e de Heine \& Claudi \& Hünnemeyer (1991).

Lakoff \& Johnson (1980) postulam que a metáfora não está limitada à nossa linguagem; ela estrutura nossos pensamentos, nos-

O corpus contém também um pequeno número de ocorrências que foram retiradas da fala de participantes de programas esportivos transmitidos pela televisão. 
Filol. lingüíst. port., n. 8, p. 113-143, 2006.

sas ações, e nosso sistema conceptual. A função primordial da metáfora é entender, conceptualizar, estruturar um domínio de nossa experiência em termos de outro. Geralmente, conceptualizamos algo menos delineado (abstrato, ou menos concreto) em termos de algo mais claramente delineado (i.e., em termos de nossas experiências mais concretas).

Os autores estabelecem três tipos de metáfora:

1) Estruturais: casos em que um conceito é metaforicamente estruturado em termos de outro.

Podemos, por exemplo, estruturar o conceito DISCUSSÃO em termos do conceito GUERRA, criando a metáfora conceptual DISCUSSÃO É GUERRA ('ARGUMENT IS WAR'). Esta, por sua vez, gera expressões metafóricas tais como Ele atacou todo ponto fraco da minha argumentação ('He attacked every weak point in my argument') (1980, p. 4).

Da mesma forma, conceptualizamos TEMPO em termos de DINHEIRO, criando o conceito metafórico TEMPO É DINHEIRO, o qual gera expressões metafóricas como Você está gastando o seu tempo ('You're wasting your time') (1980, p. 7).

2) Orientacionais: metáforas que dão a um conceito uma estruturação espacial (acima/abaixo, dentro/fora, frente/trás, etc.).

Através das metáforas orientacionais, projetamos orientações espaciais em objetos, conceitos, etc. que não têm uma orientação espacial intrínseca.

Quando utilizamos expressões metafóricas como: A bola está em frente da pedra ('The ball is in front of the rock') (1980, p. 42), estamos projetando orientações espaciais (no caso, "frente") em objetos que não têm uma frente intrínseca. Trata-se, portanto, não de uma propriedade inerente ao objeto, mas de uma propriedade interacional, que provém de nossa interação com aquele objeto. 
PEREIRA, Deize Crespim. As metáforas do futebol brasileiro.

3) Ontológicas: metáforas que permitem ver eventos, ações, estados, idéias, emoções, etc. como entidades ou substâncias.

Através das metáforas ontológicas, eventos e ações são conceptualizados metaforicamente como objetos, atividades como substâncias, estados como recipientes.

Assim, a metáfora conceptual INFLAÇÃO É UMA ENTIDADE ('INFLATION IS AN ENTITY') gera expressões metafóricas como Nós precisamos combater a inflação ('We need to combat inflation') (1980, p. 26).

Da mesma forma, CORRIDA COMO UM OBJETO RECIPIENTE ('RACE AS A CONTAINER OBJECT') produz expressões como Você está na corrida no domingo? ('Are you in the race on Sunday?') (1980, p. 31).

Entre as metáforas ontológicas, a mais facilmente percebida é aquela em que o objeto físico é especificado como sendo uma pessoa (Personificação). Isso nos permite compreender uma grande variedade de experiências com entidades não humanas em termos de motivações, características e atividades humanas (ex.: A vida me enganou) ('Life has cheated me') (1980, p. 33).

Lakoff \& Johnson (1980) também estabelecem uma distinção entre metáforas convencionais e metáforas imaginativas e criativas. Enquanto as primeiras constituem metáforas que estruturam o sistema conceitual comum de nossa cultura (ex.: AMOR É LOCURA - 'LOVE IS MADNESS'), as imaginativas e criativas são metáforas que estão fora de nosso sistema conceitual convencional (ex. AMOR É UM TRABALHO DE ARTE COOPERATIVO - 'LOVE IS A COLLABORATIVE WORK OF ART') (1980, p. 141).

Uma outra observação importante que os autores fazem é que existem muitas expressões literais estruturadas por conceitos metafóricos (ex.: Se você der as cartas certas, você pode conseguir - 'If you play your cards right, you can do it') (1980, p. 51). Esse exemplo ilustra a maneira normal, usual de falarmos sobre a vida, e se usarmos esta expressão, ela não será vista como metafórica. Ainda assim, essa 
maneira de falarmos, concebermos e experienciarmos a vida é metaforicamente estruturada - no caso, pelo conceito metafórico VIDA É UM JOGO DE AZAR ('LIFE IS A GAMBLING GAME').

Cabe notar também que esta sistematicidade, que nos permite compreender parcialmente um conceito em termos de outro, envolve tanto o ato de focalizar, como de esconder determinados aspectos desse conceito. O conceito metafórico VIDA É UM JOGO DE AZAR, por exemplo, enfatiza os aspectos imprevisíveis da vida e esconde o fato de que muitas coisas podem ser planejadas e preditas. É por esta razão que existem muitas metáforas para estruturar um mesmo conceito: cada uma delas enfatiza um aspecto específico desse conceito. A vida, por exemplo, também costuma ser metaforicamente concebida como uma história. O conceito metafórico VIDA É UMA HISTÓRIA (LIFE IS A HISTORY) é ilustrado em expressões do tipo Conte-me a história de sua vida ('Tell me the story of your life') (1980, p. 172).

Na visão de Lakoff \& Johnson, nossas experiências são estruturadas holisticamente, isto é, experiências recorrentes levam a formação de categorizações ("experiential gestalts") com dimensões naturais $^{2}$ (participantes, partes, estágios, causas, propósitos, etc.).

Cada gestalt proporciona uma base, um pano de fundo para entender uma expressão, de modo que ela faça sentido, em termos de uma categoria experiencial de nossa cultura.

Assim, uma oração como John atirou em Harry ('John fired the gun at Harry') pode ser entendida diferentemente conforme se considere a gestalt ATIRAR ('SHOOTING') ou REPRESENTAR UMA CENA CIRCENSE ('PERFORMING A CIRCUS ACT') (1980, p. 167-68).

Esses pressupostos vão ter consequiências na maneira como se entende a Semântica. Para os autores, o sentido de uma sentença não pode, portanto, ser obtido apenas pela significação de suas partes

2 Tais dimensões são vistas como naturais, porque emergem de nossa experiência, constituindo um produto de nosso corpo, e de nossa interação com o mundo físico, com outras pessoas e com a nossa cultura. 
PEREIRA, Deize Crespim. As metáforas do futebol brasileiro.

e de sua estrutura. Na perspectiva de Lakoff \& Johnson, sentenças não têm um sentido objetivo, inerente; ${ }^{3}$ e quando esses autores falam em sentido, este é sempre visto como sentido para alguém, seja ele uma pessoa real ou um membro hipotético de uma comunidade linguiística.

Quando entendemos nossa experiência metaforicamente, usamos a gestalt de um domínio da experiência para estruturar a experiência de outro domínio. Entre esses domínios, é necessário haver apenas uma relação de correspondência e não necessariamente de semelhança. As semelhanças que porventura possam existir entre os domínios da experiência que são correlacionados são, na maioria das vezes, induzidas pela metáfora. Em outras palavras, estas semelhanças não são objetivas, inerentes às entidades, mas semelhanças percebidas pelas pessoas ("experiential similarities"). Sem esse pressuposto, seria realmente impossível explicar como as pessoas concebem IDÉIAS como COMIDA em expressões metafóricas como "devorar idéias".

De qualquer forma, os autores notam que as metáforas não são arbitrárias nem aleatórias, pelo contrário, envolvem sistematicidade e coerência, pois são fundamentadas em nossa experiência (física e cultural). Os valores fundamentais em uma cultura vão ser coerentes com a estruturação metafórica dos conceitos fundamentais dessa cultura. Isso porque nossa cultura está necessariamente presente na maneira como experienciamos o mundo.

A descrição das metáforas proposta Lakoff \& Johnson (1980) não é incompatível com a apresentada por Heine \& Claudi \& Hünnemeyer (1991). ${ }^{4}$

Sob uma perspectiva semelhante, Bakhtin (1929, p. 106) postula que "o sentido da palavra é totalmente determinado por seu contexto" e que "há tantas significações possíveis quanto contextos possíveis". O problema fundamental da Semântica seria conciliar a polissemia da palavra com sua unicidade.

4 Estes dois trabalhos adotam como objeto de estudo fenômenos diferentes. Enquanto Lakoff \& Johnson (1980) dirigem a atenção para o léxico propriamente dito, Heine \& Claudi \& 
Filol. lingüíst. port., n. 8, p. 113-143, 2006.

Como notam Heine \& Claudi \& Hünnemeyer, até mesmo Sapir (1921) já observara que sendo a experiência humana infinita e os recursos da linguagem limitados, seria impossível usar uma palavra independente para expressar cada conceito. Assim, uma estratégia comum é estender o uso de formas já existentes para expressar "novos" conceitos, o que envolve o uso de recursos tais como transferência analógica, metonímia, metáfora e outros. Esses recursos servem tanto para a criação de lexemas, como de expressões gramaticais. Em outras palavras: esse processo, através do qual um objeto é expresso em termos de outro, não está restrito à gramaticalização, já que também abrange a criação de expressões metafóricas e a mudança semântica em geral. É através dele que utilizamos velhas palavras para novas funções.

Assim como Lakoff \& Johnson (1980), Heine \& Claudi \& Huinnemeyer (1991) postulam que conceitos concretos, ou mais acessíveis à experiência humana, são empregados para entender, explicar, e descrever fenômenos menos concretos, abstratos, ou menos acessíveis. Entidades claramente delineadas e estruturadas são recrutadas para conceptualizar entidades menos delineadas: a experiência não-física é entendida em termos da experiência física, tempo em termos de espaço, causa em termos de tempo, e relações abstratas em termos de processos físicos e relações espaciais (Werner \& Kaplan, 1963, in Heine et al., 1991, p. 28). Isso implica que a atividade cognitiva que leva à gramaticalização e à semanticização ${ }^{5}$ é de natureza egocêntrica e egodêitica: ela vai de domínios de conceptualização que estão próximos da experiência humana para aqueles mais distantes.

Heine \& Claudi \& Hünnemeyer (1991) igualmente estabelecem que o uso de um determinado termo linguiístico para expressar um

Hünnemeyer (1991) têm por objetivo descrever a gramaticalização (i.e., o trânsito de expressões lingüísticas do léxico para o sistema gramatical).

5 Castilho (2003) propõe que os processos de criação linguiística compreendem a gramaticalização, a lexicalização, a discursivização e a semanticização. Este último termo é utilizado para designar a criação e a alteração de sentido. 
PEREIRA, Deize Crespim. As metáforas do futebol brasileiro.

novo sentido envolve um processo através do qual dois conceitos diferentes são metaforicamente correlacionados. Esse processo de transferência conceptual, que é um ato criativo, tem dois elementos envolvidos: o conceito fonte ('source') e o conceito alvo ('target'). Enquanto o conceito alvo é geralmente algo abstrato, os conceitos fontes se referem às experiências humanas mais fundamentais; são geralmente derivados do estado físico, comportamento, ou ambiente imediato; e são frequientemente usados no pensamento e comunicação humanos.

Tal processo é motivado por propósitos comunicativos: há um novo conceito para o qual não há uma designação, ou já há uma designação, mas está "gasta”. König (1985, in Heine et al., 1991) chama a atenção também para o princípio do uso linguiístico criativo, de acordo com o qual há uma tentativa constante de expressar o mesmo sentido em outras palavras.

Heine \& Claudi \& Hünnemeyer (1991, p. 31) distinguem três tipos de criatividade: universal, comunal e individual. A primeira é comum a todos os homens, independentemente da cultura (ex.: a utilização de partes do corpo para conceptualizar espaço). A terceira é relativa ao indivíduo. No presente trabalho, interessa-nos sobretudo o segundo tipo, que tem relação com aspectos sociais, culturais e políticos de uma determinada sociedade, seus grupos étnicos, suas comunidades linguiísticas, etc. A criatividade comunal abrange a maneira como uma comunidade específica explora o domínio de objetos concretos para conceptualizar domínios abstratos.

É provável que os processos de semanticização e gramaticalização se iniciem com a criatividade individual, que em condições específicas leva a criatividade comunal. $O$ processo de criação de expressões metafóricas é, sem dúvida, um ato criativo, que tem origem em um indivíduo. Tais metáforas são posteriormente propagadas na comunidade linguiística. No caso específico das metáforas do futebol, isso ocorre principalmente através da mídia. 
O termo "metáfora" tem sido usado com muitos significados. ${ }^{6}$ Ele pode ser empregado como um termo abrangente para qualquer figura de linguagem. Heine \& Claudi \& Hünnemeyer (1991, p. 46) apontam alguns de seus aspectos gerais:

(i) a metáfora abrange um sentido que é chamado "literal" e outro denominado "transferido" ou "metafórico";

(ii) ela envolve uma transferência - ou um mapeamento de um esquema imagético (“image schema") (Sweetser, 1988, in Heine et al., 1991) - de um domínio da conceptualização para outro;

(iii) o conceito fonte é mais facilmente entendido do que o conceito alvo; ${ }^{7}$

(iv) a metáfora "estende a linguagem além do seu limite elástico" ("streches language beyond its elastic limit");

(v) é comumente vista como uma afirmação falsa ou errônea, que vai contra as nossas expectativas (cf. Winner, 1979; Davidson, 1979; Ricouer, 1979, Swanson, 1979, in Heine et al., 1991);

(vi) uma característica comum da metáfora é que, em contextos específicos, ela pode também ser entendida no sentido literal, o que pode resultar em ambiguiidade;

(vii) há às vezes uma motivação icônica que subjaz a metáfora (ex.: a conceptualização de tempo em termos de espaço teria origem na relação entre objetos se movendo no espaço e situações se desenvolvendo através do tempo).

\footnotetext{
Muitos autores vêem a gramaticalização como um subtipo de metáfora (cf. Matisoff, in press; Bybee \& Pagliuca, 1985; Willet, 1988; Ransom, 1988; in Heine et al., 1991).

7 Levinson (1983, p. 45, in Heine et al., 1991: 45) nota que: "For if metaphors is like a model, or a map, or a analogue of a domain, then just like models, maps and analogues in general, if they are to be useful and successful, metaphors had better be simpler, idealized, more easily grasped than the complex domain that they model."
} 
PEREIRA, Deize Crespim. As metáforas do futebol brasileiro.

Heine \& Claudi \& Hünnemeyer (1991) também distinguem diversos tipos de metáfora. Levando em conta a sua função, elas são classificadas em:

1) Metáforas experienciais ("Experiential metaphor"), cuja função é descrever e entender fenômenos abstratos ou conceitualmente complexos em termos de fenômenos concretos ou menos complexos;

2) Metáforas expressivas (“Expressive metaphors”): servem para enriquecer a expressividade de uma enunciação;

3) Metáforas tabus ("Taboo metaphors"): servem para esconder, obscurecer a realidade (Claudi \& Heine, 1986, in: Heine et al., 1991, p. 50). ${ }^{8}$

Uma outra distinção diz respeito à sua origem:

1) Metáforas criativas ("Creative metaphor"): uma nova expressão é formada contendo uma predicação falsa, errônea, que conflita com nossas expectativas, e implica uma violação intencional de regras semânticas e conceptuais. Idealmente tal expressão nunca foi dita antes (ex.: metáfora da física: "um átomo é um sistema solar");

2) Metáforas emergentes ("Emergent metaphors"): não formam expressões novas, mas sim construídas a partir de predicações preexistentes. Estas, que geralmente constituem predicações frequentemente usadas, são introduzidas em novos contextos e aplicadas a novas situações, criando

8 Apesar de muitos estudiosos argumentarem que os processos metafóricos, como observados na linguagem, são os mesmos independentemente do fato de estarmos lidando com material léxico ou gramatical, Heine et al. (1991) estabelecem que o léxico permite os três tipos de metáfora propostos acima, já as categorias gramaticais só envolvem metáforas experienciais. Uma outra diferença entre estes é que enquanto o desenvolvimento de morfemas gramaticais é unidirecional (dos sentidos concretos para os mais abstratos), o desenvolvimento no léxico não tem esta restrição. 
Filol. lingüíst. port., n. 8, p. 113-143, 2006.

assim um sentido por extensão (ex.: to clean the slate, 'apagar a lousa'; to have a clean slate 'ter uma ficha limpa') (Heine et al., 1991, p. 60).

De acordo com os autores, em (2), o veículo metafórico é uma extensão conceptual do tópico; já (1) envolve domínios conceptuais inteiramente distintos. Heine et al. (1991) ressaltam também que a nomenclatura utilizada não implica que as metáforas emergentes não envolvam criatividade.

Os autores esclarecem que, sob uma perspectiva sincrônica, nem sempre é possível determinar com precisão se uma metáfora é criativa ou emergente, propondo que se considerem estes dois tipos de metáfora como pontos extremos de um continuum.

As metáforas emergentes são pragmaticamente motivadas. Elas devem sua existência a implicaturas conversacionais e reinterpretações induzidas pelo contexto. Essas reinterpretações são descritas como envolvendo os seguintes estágios:

(i) Estágio 1: em adição a um sentido focal ou núcleo A, uma determinada forma linguiística adquire um sentido adicional $\mathrm{B}$, quando ela ocorre em um contexto específico C. Isso pode resultar em ambiguiidade, e qual dos dois sentidos é o implicado dependerá da situação comunicativa em questão.

(ii) Estágio 2: a existência do sentido B torna possível que a forma seja usada em contextos que só admitem o sentido B.

(iii) Estágio 3: o sentido B é convencionalizado, é o segundo sentido focal, caracterizado por propriedades não contidas no sentido A. Isso resulta em polissemia e homofonia (1991, p. 71).

O estágio (iii) implica que o sentido focal pode variar conforme o contexto; e em vários casos é possível predizer qual dos sen- 
PEREIRA, Deize Crespim. As metáforas do futebol brasileiro.

tidos vários é focal, levando em conta o contexto. Em outras palavras, o sentido não focal, em um contexto específico, pode tornarse focal: "Whereby some nonfocal sense is highlighted in a specific context and develop into a new focal sense" (1991, p. 101).

As reinterpretações induzidas pelo contexto são relacionadas, entre outros, a: (i) perspectivização, que é uma estratégia cognitiva através da qual diferentes usos da forma tendem a focalizar diferentes componentes ou sentidos daquela forma; (ii) esquematização - as similaridades entre os sentidos A e B são ressaltadas, e as diferenças postas em segundo plano (1991, p. 72).

Heine \& Claudi \& Hünnemeyer (1991, p. 48) propõem ainda uma escala de metáforas categoriais (domínios de conceptualização que estruturam a experiência), que pode ser útil em nossa análise:

$$
\text { PESSOA }>\text { OBJETO }>\text { ATIVIDADE }>\text { ESPAÇO }>\text { TEMPO }>\text { QUALIDADE }
$$

De acordo com os autores, uma determinada categoria é mais abstrata do que qualquer outra à sua esquerda, e menos abstrata do que a que a segue. Cada uma delas serve para conceptualizar qualquer uma das categorias à sua direita.

Comparando-as com as metáforas conceptuais de Lakoff \& Johnson (1980), notamos que as metáforas categoriais ${ }^{9}$ de Heine et al. (1991) são mais abrangentes, mais inclusivas. Assim, por exemplo, as metáforas conceptuais do tipo orientacional propostas por Lakoff \& Johnson (1980), que têm em comum o uso de "up-down" como veículo metafórico (exs.: HAPPY IS UP, SAD IS DOWN, etc.), podem ser agrupadas em uma das metáforas categoriais sugeridas por Heine et al. (1991): ESPAÇO > QUALIDADE (i.e., situações, estados, ou qualidades são metaforicamente conceptualizados em termos de conceitos locativos).

As metáforas categoriais podem abranger sentenças inteiras, proposições, conceitos ou tipos de contextos em que um conceito é usado. 
Filol. lingüíst. port., n. 8, p. 113-143, 2006.

Também a Personificação proposta por Lakoff \& Johnson (1980), na perspectiva de Heine et al. (1991), é vista como envolvendo as metáforas categoriais PESSOA > OBJETO (i.e., entidades [- humanas] e [- animadas] são conceptualizadas em termos de seres [+ humanos]).

Cada uma dessas categorias propostas por Heine et al. representa, portanto, um domínio elementar da experiência humana. Elas são ligadas umas às outras através de uma atividade cognitiva, que é a metáfora. Essa correlação entre diferentes domínios conceptuais constitui uma operação abstrata.

Heine et al. (1991, p. 43) propõem três tipos de abstração: (i) abstração generalizante: reduz os traços de um conceito para o núcleo ou suas características centrais; (ii) abstração isoladora: separa uma característica particular do conceito, que não é necessariamente o núcleo; (iii) abstração metafórica: relaciona conteúdos mais abstratos a mais concretos, entre diferentes domínios conceptuais. O conteúdo mais concreto é utilizado como um veículo metafórico para os abstratos.

Essa operação abstrata pressupõe um ato de criatividade que seja capaz de relacionar os conceitos a novos contextos: "creativity requires speakers to manipulate context and concepts in a way that is intelligible and is eventually adopted by the speech community" (1991, p. 93). Para os autores, no entanto, não está claro se o contexto condiciona a criatividade ou se a criatividade manipula o contexto. De qualquer forma, uma expressão como o pé da montanha, por exemplo, implica necessariamente um ato criativo, envolvendo a transferência metafórica de propriedades humanas para conceitos inanimados. ${ }^{10}$

Traugott \& König (in press, In. Heine et al. 1991, p. 70,74) relacionam a mudança semântica implicada na metáfora à questão da representação: "metaphor is largely correlated with shifts from meanings situated in the external described situation to meanings situated in the internal evaluative, perceptual, cognitive situation, and in textual situation". 
PEREIRA, Deize Crespim. As metáforas do futebol brasileiro.

Todos esses pressupostos propostos por Heine et al. (1991) e Lakoff \& Johnson (1980) podem ser aplicados às metáforas do futebol.

Neste trabalho, só analisaremos metáforas convencionais, isto é, que fazem parte da maneira normal, usual de falar sobre futebol em nossa sociedade. São expressões fixadas pela convenção.

Realizaremos uma análise qualitativa de um corpus composto por 316 ocorrências efetivamente realizadas por profissionais do futebol brasileiro, adotando o método da introspecção, o qual é sugerido por Talmy (2003) e Greimas (1976).

Em cada caso, faremos especulações sobre como cada conceito metafórico pode ter surgido, tomando por base nossa experiência física e cultural. Essas especulações são hipóteses plausíveis, sugestivas, mas não definitivas. O objetivo é reconstruir a atividade cognitiva, como ela estrutura o uso dessas metáforas, de um ponto de vista sincrônico.

\section{ANÁLISE DOS DADOS}

\section{1 Metáforas estruturais, orientacionais e ontológicas}

Em um primeiro momento de nossa análise, procuramos verificar quais metáforas estruturais, orientacionais e ontológicas (Lakoff \& Johnson, 1980) poderiam ser encontradas no corpus. Vejamos os resultados:

\section{I) Metáforas estruturais}

A metáfora conceitual Futebol é uma guerra é a dominante, a que gera o maior número de expressões no corpus. Essa metáfora evidencia claramente que o conceito futebol é parcialmente estruturado e entendido em termos de guerra. O vocabulário utilizado pelos narradores das partidas contém um grande número de palavras características de uma guerra: 
Filol. lingüíst. port., n. 8, p. 113-143, 2006.

a) ataque, campo de ataque, atacar, atacante:

(1) Olha o time do Corinthians partiu pro ataque (Corinthians x Santos, TV Globo, 06/11/2005)

(2) Vem bola pro campo de ataque da equipe do Botafogo (Corinthians x Botafogo, Rádio Transamérica, 28/08/2005)

(3) O Souza não está atacando (São Paulo x Paulista, TV Globo, 06/03/2005)

(4) $\mathrm{O}$ atacante do Inter veio aqui à beira do campo pediu pra sair (Corinthians x Inter, TV Globo, 20/11/2005)

b) contra-ataque, contra-golpe:

(5) Ficaram dois jogadores do Santos pro contra-ataque (Flamengo x Santos, TV Cultura, 13/11/2005)

(6) E dá-lhe dá-lhe dá-lhe contra-ataque (Corinthians $x$ Santos, Rádio Transamérica, $2^{\circ}$ tempo, 06/11/2005)

(7) [o Corinthians] não quer se expor ao contra-ataque (Corinthians $x$ Inter, TV Globo, 20/11/2005)

(8) Pode pintar mais um gol do Náutico no contra golpe (Portuguesa x Náutico, Rede TV, 19/11/2005)

c) defesa, campo de defesa, defender:

(9) Sai Silvio Luis do gol pra fazer a defesa (Corinthians $x$ São Caetano, Rádio Transamérica, 23/03/2005)

(10) O time do Internacional jogando no campo de defesa (Corinthians x Inter, Rádio Transamérica, 20/11/2005)

(11) Defendeu Fábio Costa (Corinthians x Palmeiras, Rádio Transamérica, 20/03/2005)

d) artilheiro:

(12) Cê acha que o Tevez vai sê o artilheiro do campeonato? (Programa Gazeta esportiva, TV Gazeta, 06/11/2005) 
PEREIRA, Deize Crespim. As metáforas do futebol brasileiro.

(13) Romário é o vice-artilheiro (Corinthians x Inter, TV Globo, 20/11/2005)

e) bomba, explodir:

(14) Chuta uma BOM: ::ba uma bomba (São Paulo x Portuguesa, TV Gazeta, 31/03/2005)

(15) uma bomba a bola explodiu pra cima do Gustavo Nery (Corinthians x Ponte, TV Globo, 27/11/2005)

(16) A bola explodiu no peito do Rogério Ceni (São Paulo x Quilmes,TV Globo, 16/03/2005)

f) tiro:

(17) É tiro de meta tiro de gol pro Cruzeiro (Corinthians $\mathrm{x}$ Cruzeiro, Rádio Transamérica, 02/11/2005)

(18) Falhô o goleiro falhô porque nu foi um tiro forte do Almir (Grêmio x Portuguesa, Rede TV, 12/11/2005)

g) perigo, perigoso:

(19) Um ataque perigosíssimo do Paulista (São Paulo x Paulista, TV Globo, 06/03/2005)

(20) Falta perigosíssima olha a chance do Timão no lance (Corinthians x Botafogo, Rádio Transamérica, 28/08/2005)

(21) Escanteio batido bola perigosa (Corinthians x Cruzeiro, Rádio Transamérica, 02/11/2005)

(22) Ele [Luisão] é sempre perigoso (Corinthians x Santos, TV Globo, 06/11/2005)

(23) Essa foi a jogada mais perigosa do Santos no primeiro tempo (Flamengo x Santos, TV Cultura, 13/11/2005)

(24) Carlos Alberto abriu bateu e ela [a bola] passa com perigo (Corinthians $x$ Inter, TV Globo, 20/11/2005, $2^{\circ}$ tempo)

(25) Olha o Internacional chegando com perigo (Corinthians x Inter, TV Globo, 20/11/2005) 
Filol. lingüíst. port., n. 8, p. 113-143, 2006.

h) matar, morrer:

(26) Por baixo Anderson mata a jogada (Corinthians x Palmeiras, Rádio Transamérica, 20/03/2005)

(27) Aí vem trabalhando o time do Goiás ... nu tá morto nu jogo não (Corinthians x Goiás, TV Globo, 04/11/2005)

i) desarmar, armar:

(28) Magrão é desarmado (Corinthians x Palmeiras, Rádio Transamérica, 20/03/2005)

(29) Desarma o time adversário (Corinthians x Cianorte, Rádio Transamérica, 31/03/2005)

(30) Vem Bruno Otávio desarmando o ataque do time colorado (Corinthians x Inter, Rádio Transamérica, 20/11/ 2005)

(31) Tenta armar outra vez o ataque, mete pela linha lateral (Corinthians x Inter, Rádio Transamérica, 20/11/2005)

j) engatilhar, disparar, descarregar, fuzilar:

(32) Tevez dominô engatilhô (Corinthians x Palmeiras, Rádio Transamérica, 20/03/2005)

(33) Bola disparada... vai pela linha de fundo (Corinthians $x$ Santos, Rádio Transamérica, $2^{\circ}$ tempo, 06/11/2005)

(34) Fabinho tenta descarrega outra vez pro campo de ataque (Corinthians x Santos, Rádio Transamérica, $2^{\circ}$ tempo, $06 / 11 / 2005)$

(35) Deu um drible na cara do Rogério e fuzilô (São Paulo x Paulista, TV Globo, 06/03/2005)

k) dominar:

(36) Eduardo domina pelo campo de defesa (Corinthians $\mathrm{x}$ Santos, Rádio Transamérica, $2^{\circ}$ tempo, 06/11/2005) 
PEREIRA, Deize Crespim. As metáforas do futebol brasileiro.

(37) E a bola dominada pela equipe do Corinthians (Corinthians x Inter, Rádio Transamérica, 20/11/2005)

l) perder, ganhar, invadir território:

(38) O Corinthians começô a perdê o meio de campo (Corinthians x Inter, TV Globo, 20/11/2005)

(39) Tevez invadiu a área... corta Daniel (Corinthians x Palmeiras, Rádio Transamérica, 16/10/2005)

m) massacre:

(40) O massacre no Pacaembu [Corinthians 7 x Santos 1] (Programa esportivo, TV Bandeirantes, 06/11/2005)

n) combate:

(41) O Wendel é o primeiro a dá combate (Corinthians x Inter, Rádio Transamérica, 20/11/2005)

Essas expressões constituem uma maneira tão comum de falar sobre futebol, que são tomadas como descrições diretas do jogo. Os exemplos acima, no entanto, indicam claramente que a metáfora conceptual Futebol é uma guerra comanda grande parte das expressões que são utilizadas para narrar as partidas. Mas essa metáfora não está presente somente nas palavras que usamos para falar de futebol. Conforme Lakoff \& Johnson, se nós falamos dessa maneira, é porque concebemos o futebol como uma guerra. O conceito guerra é, segundo os autores, um dos mais presentes na cultura humana, e não é de se admirar o fato de que em um jogo que envolve disputa entre dois times que se vêem como oponentes, seja largamente empregado.

Fighting is found everywhere in the animal kingdom and nowhere so much as among human animals. Animals fight to get what they want - food, sex, territory, control, etc. - because there are other animals who want the same thing or who want to stop them from getting it. The same is true of 
Filol. lingüíst. port., n. 8, p. 113-143, 2006.

\begin{abstract}
human animals, except that we have developed more sophisticated techniques for getting our way. Being 'rational animals' we have institutionalized our fighting in a number of ways, one of them being war. Even though we have over the ages institutionalized physical conflict and have employed many of our finest minds to develop more effective means of carrying it out, its basic structure remains essentially unchanged. In fights between two brute animals, scientists have observed the practices of issuing challenges for the sake of intimidation, of establishing and defending territory, attacking, defending, counterattacking, retreating and surrendering. Human fighting involves the same practices. (Lakoff \& Johnson, 1980, p. 61-2)
\end{abstract}

Examinando o corpus, pudemos verificar também a existência de outras metáforas estruturais, ainda que as ocorrências que as representam sejam em número bem menor do que as relativas à metáfora conceptual Futebol é uma guerra vista acima. São elas:

- Futebol é um comércio. Exs.:

(42) O Lugano tá vendido no jogo (São Paulo x Paulista, TV Globo, 06/03/2005)

(43) A falta vai sê cobrada pelo Lucas (São Paulo x Paulista, TV Globo, 06/03/2005)

(44) Campanolo vai virando freguês de Rogério Ceni (São Paulo x Tigres, TV Globo, 02/06/2005)

(45) Rifa o lance (Corinthians x Cruzeiro, Rádio Transamérica, $02 / 11 / 2005)$

(46) É tiro de meta tiro de gol pro Cruzeiro fazer a cobrança (Corinthians x Cruzeiro, Rádio Transamérica, 02/11/2005)

(47) Errado o ataque do Leandro Amaral de graça pro goleiro do Náutico (Portuguesa x Náutico, Rede TV, 19/11/2005)

(48) A barreira abre aí o goleiro fica vendido não tem jeito (Portuguesa x Náutico, Rede TV, 19/11/2005)

(49) Aluga o meio do campo (Barcelona x Real Madrid, TV Bandeirantes, 19/11/2005) 
PEREIRA, Deize Crespim. As metáforas do futebol brasileiro.

(50) Com certeza ficou devendo Robinho (Barcelona x Real Madrid, TV Bandeirantes, 19/11/2005)

(51) Não vê a cor da bola Romário (Corinthians x Vasco, Rádio Transamérica, 30/10/2005) ${ }^{11}$

- Futebol é uma religião. Exs.:

(52) São Marcos opera milagres ... Palmeiras 3 Santos 1 (Programa Bola na Rede, Rede TV, 06/03/2005)

(53) Milagre de Gléguer (São Paulo x Portuguesa, Rádio Transamérica, 31/03/2005)

(54) Salvô espetacularmente o goleiro (Corinthians x Cruzeiro, Rádio Transamérica, 02/11/2005)

- Futebol é uma pintura. Exs.:

(55) A gente tá vendo de novo essa obra-prima do Ronaldo (Barcelona x Real Madrid, TV Bandeirantes, 19/11/2005)

(56) Uma pintura de gol (Barcelona x Real Madrid, TV Bandeirantes, 19/11/2005)

(57) O Corinthians joga uma belíssima partida (Corinthians $\mathrm{x}$ Inter, Rádio Transamérica, 20/11/2005)

- Futebol é uma dança. Exs.:

(58) Tá chamando pro baile Carlitos (Santo André x Corinthians, Rádio Transamérica, 13/03/2005)

(59) Wesley hoje nu tá bem tomô um baile ali do William (Corinthians x Vasco, Rádio Transamérica, 30/10/2005)

(60) Uma jogada ensaiada do Grêmio (Grêmio x Portuguesa, Rede TV, 12/11/2005)

11 Por analogia a "não vê a cor do dinheiro". 
Filol. lingüíst. port., n. 8, p. 113-143, 2006.

(61) Vai embora o Carlos Alberto deu mais uma gingada (Corinthians x Inter, TV Globo, 20/11/2005)

(62) O Flamengo tá na base do bumba-meu-boi... só desespero (Flamengo x Santos, TV Cultura, 13/11/2005)

\section{II) Metáforas orientacionais}

As metáforas orientacionais exercem um papel fundamental na descrição do jogo, especialmente quando a transmissão é radiofônica. É por meio delas, que o ouvinte consegue "visualizar" a jogada, mesmo que este não esteja assistindo à partida. Várias orientações espaciais são projetadas no campo de futebol, como ilustram os exemplos a seguir:

a) Campo plano > campo oblíquo:

(63) O Corinthians tá descendo pro jogo (Santo André x Corinthians, Rádio Transamérica, 13/03/2005)

(64) Vai subindo o time do Grêmio (Grêmio x Portuguesa, Rede TV, 12/11/2005)

b) Não tem frente/trás intrínsecas $>$ portador de frente/trás (essas orientações são relativas ao time que está com a bola):

(65) Ninguém acompanhou o ataque lá na frente (Flamengo $\mathrm{x}$ Santos, TV Cultura, 13/11/2005)

(66) Vem de trás o Perdigão (Corinthians x Inter, TV Globo, 20/11/2005)

c) Não-recipiente > Recipiente:

(67) Bola disparada... vai pela linha de fundo (Corinthians $x$ Santos, Rádio Transamérica, $2^{\circ}$ tempo, 06/11/2005)

(68) O Rômulo fica ali na entrada da área espera o passe também (Flamengo x Santos, TV Cultura, 13/11/2005) 
PEREIRA, Deize Crespim. As metáforas do futebol brasileiro.

(69) Tevez leva a bola por dentro (Corinthians x Inter, TV Globo, 20/11/2005)

(70) O jogo cresce ...a Portuguesa começa a sair mais (Grêmio x Portuguesa, Rede TV, 12/11/2005)

O espaço percorrido pela bola e a disposição dos jogadores no campo também são metaforicamente descritos:

(71) Bola fechada na grande área (Corinthians x São Caetano, Rádio Transamérica, 23/03/2005)

(72) Aí o levantamento... bola aberta... escanteio mal cobrado (Grêmio x Portuguesa, Rede TV, 12/11/2005)

(73) Meteu errado ... bola muito comprida (Corinthians x Inter, Rádio Transamérica, 20/11/2005)

(74) Danilo cobrô [o escanteio] curtinho (São Paulo x Paulista, TV Globo, 06/03/2005)

(75) Eduardo abriu pra Dinelson (Corinthians x Santos, Rádio Transamérica, $2^{\circ}$ tempo, 06/11/2005)

(76) Bola cruzada Jô fechava pra tentar concluir (Corinthians x Santos, Rádio Transamérica, $2^{\circ}$ tempo, 06/11/2005)

(77) Se abre o Flamengo... o Santos vai... são três contra dois (Flamengo x Santos, TV Cultura, 13/11/2005)

(78) Vem embora Gustavo (Corinthians x Inter, TV Globo, 20/ $11 / 2005)$

Além disso, o campo de futebol é figurativamente visto como uma rua, ou avenida; havendo, portanto, uma sobreposição das metáforas orientacional e estrutural:

(79) Do meio da rua Roger meteu no ângulo (Corinthians $x$ União São João, Rádio Transamérica, 05/03/2005)

(80) O quê? Chutá do meio da avenida ali... será que dá? (Corinthians x São Paulo: Rádio Transamérica, 24/10/2005) 
Filol. lingüíst. port., n. 8, p. 113-143, 2006.

\section{III) Metáforas ontológicas}

A personificação é uma estratégia recorrente nas narrações. Através dela, objetos (a trave de gol, a bola), espaços estratégicos do campo de futebol (a grande área), e ações (o jogo, o gol, a falta) são tratados metaforicamente como entidades [+ animadas] e [+ humanas]. Na descrição dos exemplos abaixo, utilizamos as metáforas categoriais de Heine et al (1991).

PESSOA > OBJETO:

(81) Robinho deixa David na cara do gol (Programa Bola na Rede, Rede TV, 06/03/2005)

(82) Levantamento na boca do gol ... pra fora (Portuguesa x Náutico, Rede TV, 19/11/2005)

(83) Bateu na orelha da bola... será que a bola tem orelha? (Corinthians x River, TV Globo, 15/09/2005)

(84) Toca a bola pra linha de fundo venenosa (Corinthians $x$ União São João, Rádio Transamérica, 05/03/2005)

(85) A bola desviou na barreira e enganou o goleiro (Portuguesa x Náutico, Rede TV, 19/11/2005)

(86) Lá vai ela [a bola] dentro da grande área do Corinthians (Corinthians x Inter, TV Globo, 20/11/2005)

(87) Bateu pro gol e ela [a bola] vai embora pela linha de fundo (Corinthians x Inter, TV Globo, 20/11/2005)

(88) Lucas mata [a bola] no peito (São Paulo x Paulista, TV Globo, 06/03/2005)

(89) A barreira se mexe... [a bola] passa pela barreira e morre no fundo do gol (Portuguesa x Náutico, Rede TV, 19/11/ $2005)^{12}$

12 A expressão "a barreira se mexe" poderia ser descrita como compreendendo as metáforas categoriais OBJETO $>$ PESSOA (i.e., os jogadores são metaforicamente vistos como uma barreira) e PESSOA > OBJETO (i.e., a barreira é conceptualmente interpretada como portadora de movimento e portanto [+ animada]). 
PEREIRA, Deize Crespim. As metáforas do futebol brasileiro.

PESSOA > ESPAÇO:

(90) A falta no bico da grande área do Corinthians (Corinthians x Inter, Rádio Transamérica, 20/11/2005)

PESSOA > ATIVIDADE:

(91) O jogo cresce ... a Portuguesa começa a sair mais (Grêmio x Portuguesa, Rede TV, 12/11/2005)

(92) E a moral que deve dá esse gol (Corinthians x Inter, TV Globo, 20/11/2005)

(93) Chamô a falta (Inter x Porto, Rede TV, 15/03/2005)

Essas metáforas são frequientes no futebol. ${ }^{13}$ Não sabemos até que ponto os narradores têm consciência de que estão utilizando uma linguagem metafórica. Reflexões de natureza metalinguística, como em (83), são raríssimas. Em nosso corpus, encontramos apenas uma ocorrência em que isto acontece.

\subsection{Base experiencial das metóforas: Conceito Fonte e Conceito Alvo}

Neste item, examinamos as bases experienciais de algumas metáforas, procurando verificar quais conceitos fontes são empregados, e as relações que podem ser estabelecidas entre conceito fonte e conceito alvo.

Além da guerra, vista no item anterior, existe um outro domínio que é frequentemente utilizado no futebol. Trata-se do reino animal. O domínio dos bichos é largamente usado para fazer referência aos times e às torcidas. ${ }^{14}$ Mas é sobretudo para descrever as

13 Há muitas outras expressões (não registradas no corpus) que ilustram estas três categorias. É o caso de "a bola procura o craque" (PESSOA>OBJETO), "morrinho artilheiro" (PESSOA>ESPAÇO), e "gol espírita" (PESSOA>ATIVIDADE).

14 Ainda que nosso corpus não contenha exemplos deste uso, sabemos que são comuns expressões como: "Bambi" (aludindo ao veado personagem da Disney), para aludir aos 
Filol. lingüíst. port., n. 8, p. 113-143, 2006.

jogadas, que nomes de bichos são comumente utilizados. Vejamos alguns exemplos:

(94) O Coelho chutô onde a coruja dorme (Programa Bola na Rede, Rede TV,06/03/2005)

(95) O Roger armô uma cama de gato (Corinthians x River, TV Globo, 28/09/2005)

(96) Gil deu o drible da vaca no Emerson (Programa Terceiro Tempo, TV Record, 20/03/2005)

(97) Ele toma um gol que às vezes não dá pra pegá... as pessoas falam que é frango... eu vi Gilmar dos Santos Neves tomá frango (Programa Bola na Rede, Rede TV, 06/03/ 2005)

(98) Tomô um peru... nu foi um peruzaço daquele (Corinthians x Brasiliense, Rádio Transamérica, 02/10/2005)

Nos exemplos (94) e (95), as expressões parecem, à primeira vista, ser portadoras do traço [+ ESPAÇO], marcando respectivamente o lugar onde dormem a coruja e o gato. "Onde a coruja dorme" denota efetivamente um espaço da trave do gol, o chamado "ângulo". Já "cama de gato" denota não um espaço, mas uma ação, sendo esta metáfora utilizada quando o jogador se apóia no corpo do adversário, caindo sobre ele. A expressão pode estar aludindo à "malandragem" e "esperteza" que tradicionalmente atribuímos ao gato.

torcedores e jogadores do São Paulo; "porco" para os palmeirenses, "peixe" para os santistas, "galo" para o time do Atlético Mineiro, e "canarinho" para a seleção brasileira. Alguns destes empregos datam de uma época recente. Os palmeirenses, por exemplo, tinham como símbolo o periquito há um tempo atrás, e muitos torcedores não aceitam a nova designação. A expressão "Bambi" para fazer referência ao time do São Paulo também é recente. Ela foi empregada pela primeira vez na mídia por um jogador do Corinthians, e embora isto tenha causado uma grande polêmica, seu uso logo se espalhou. 
PEREIRA, Deize Crespim. As metáforas do futebol brasileiro.

As expressões metafóricas "drible da vaca" e "tomar um frango" ou "peru", vistas em (96-98), têm uma forte motivação icônica. O "drible da vaca" consiste em enganar o jogador adversário, como o toureiro faz com o touro, em uma tourada. "Tomar um frango", por sua vez, remete à experiência de apanhar um frango. ${ }^{15}$ Todos que já tentaram realizar esta tarefa sabem como é difícil executá-la. No futebol, porém, "tomar um frango" significa não conseguir pegar uma bola que seria relativamente fácil de pegar, resultando em gol do time adversário. Há aqui, portanto, uma correlação entre gestalts, isto é, domínios distintos de nossa experiência.

Vejamos as ocorrências a seguir, as quais descrevem dribles:

(99) Faiz fila o jogador do Corinthians (Santo André x Corinthians, Rádio Transamérica, 13/03/2005)

(100) Jogada número três um lindo chapéu e um golaço (Programa Esporte Interativo, TV Bandeirantes, 06/03/2005)

(101) [Ronaldinho] deu um elástico (Brasil x Peru, TV Globo, 27/03/2005)

(102) O Carlos Alberto pegou a bola já deu uma caneta no Marcinho (Corinthians x Palmeiras, Rádio Transamérica, 20/03/2005)

A expressão "fazer fila" tem o significado de dar uma sequiência de dribles. É como se os jogadores oponentes estivessem dispostos em uma fila, esperando para serem driblados. Como nos exemplos vistos acima, ocorre a utilização de um domínio familiar de nossa experiência para conceptualizar as jogadas do futebol.

Os exemplos (100-102) podem ser analisados como compreendendo a metáfora categorial OBJETO > ATIVIDADE (Heine et al, 1991). Os objetos chapéu, elástico, e caneta são metaforicamente

5 Essa base experiencial é comprovada pela expressão "o goleiro ficou com as penas na mão", que embora seja de uso comum, não foi registrada no corpus. 
empregados para conceptualizar uma ação. Há aqui novamente uma motivação icônica. $\mathrm{O}$ "chapéu" consiste em passar a bola por sobre a cabeça do jogador adversário. Imitando o movimento de um elástico, que tem a propriedade física de esticar e voltar ao estado inicial, o "drible do elástico" consiste em levar a bola para a frente e trazê-la de volta com o mesmo pé, enganando o adversário. A " $c a$ neta" por sua vez remete às pernas do jogador; "dar" ou "meter uma caneta" significa passar a bola entre as pernas do oponente. Note-se que a metáfora, nesses casos, facilita enormemente o trabalho do narrador, já que empregando uma única palavra, ele é capaz de descrever toda uma cena.

Essas semelhanças experienciais (Lakoff \& Jonhson, 1980) entre conceito fonte e conceito alvo podem ser percebidas em muitas outras expressões metafóricas encontradas no corpus:

(103) O Marcos mergulha pra dá um soco na bola (Santos x Palmeiras, TV Globo, 06/03/2005)

(104) Aquelas pedalada dele [do Robinho] é animal (Programa Terceiro Tempo, TV Record, 06/03/2005)

(105) Ele é o carregador de piano (Corinthians x Inter, Rádio Transamérica, 20/11/2005)

(106) Se ele dá uma paradinha vai levá um carrinho seria pênalti (Goiás x Corinthians, TV Globo, 04/12/2005)

"Mergulhar" descreve a expressão corporal do jogador, quando imita o movimento de um mergulho. "Pedalar" remete ao drible que lembra o movimento de pedalar em uma bicicleta. A expressão "carregador de piano" é usada para referir ao jogador que não é a estrela do time, mas ajuda ativamente os seus companheiros na marcação. Embora não registrada no corpus, uma outra expressão que tem um sentido semelhante a esse é "garçom" (i.e., o jogador que "serve" os seus companheiros, isto é, dá assistência para que eles possam fazer gols). A metáfora "Levar um carrinho", por fim, é 
PEREIRA, Deize Crespim. As metáforas do futebol brasileiro.

utilizada quando o adversário chega por baixo atingindo as pernas do jogador e fazendo falta, atropelando-o por assim dizer. Assim temos: "levar um carrinho" ('ser atropelado') e "dar um carrinho" ('atropelar').

Muitas das expressões metafóricas vistas até aqui são do tipo emergente (Heine et al., 1991), já que têm um sentido por extensão, que já estava implicado de algum modo no conceito fonte.

Mas há também metáforas criativas, que desviam de nossas expectativas, uma vez que "violam" regras semânticas e conceptuais. Além da expressão "cama de gato", vista no exemplo (95), temos:

(107) Belo gol... driblô o Lugano... encheu o pé (São Paulo x Paulista, TV Globo, 06/03/2005)

(108) O Roger gastou a bola (Programa Bola na Rede, Rede TV, 06/03/2005)

(109) Marcos vira um paredão (Programa Bola na Rede, Rede TV, 06/03/2005)

(110) Nossa [a bola] chegô quadrada e Leandro arredondô (Corinthians x Pumas do México, TV Record, 09/11/2005)

(111) Que pancada o chamado tijolo quente (Santos x São Paulo: $2^{a}$ divisão, TV Cultura, 17/09/2005)

(112) Chocolate alvinegro em cima do Santos aqui no Pacaembu (Corinthians x Santos, Rádio Transamérica, $2^{\circ}$ tempo, 06/11/2005)

(113) Foi um gol chorado (Programa Esportivo Bola na Rede, Rede TV, 04/11/2005)

(114) Falta do João Alex que deixou o corpo (Flamengo x Santos, TV Cultura, 13/11/2005)

(115) Olha o Pereira aí cheio de graça... gira limpa a jogada (Grêmio x Portuguesa, Rede TV, 12/11/2005)

(116) O Tevez chutô na lua o pênalti (Corinthians x Ponte, TV Bandeirantes, 27/11/2005) 
Filol. lingüíst. port., n. 8, p. 113-143, 2006.

Essas instâncias, juntamente com os exemplos de personificação vistos no item anterior, constituem expressões que só são empregadas no futebol. São metáforas que se encaixam com a definição de afirmação errônea ou falsa, que vai contra as nossas expectativas. Ainda assim, elas evocam imagens que podemos imaginar e que facilitam a descrição do jogo. Esclarecemos aqui os significados das expressões vistas acima: encher o pé ('chutar forte'), gastar a bola ('participar ativamente do jogo', 'jogar bem'), virar um paredão ('“fechar” o gol, defender as bolas, evitando o gol do adversário'), arredondar uma bola que chegou quadrada ('receber um mau passe e dar um bom passe'), tijolo quente ('chute forte, indefensável'), chocolate ('goleada, festa'), gol chorado ('gol que demorou a sair'), deixar o corpo ('fazer falta, empurrar o oponente com o corpo'), limpar a jogada ('livrar-se da marcação dos adversários'), chutar na lua ('não acertar o gol, chutar muito longe do gol').

\section{CONSIDERAÇÕES FINAIS}

A análise das metáforas encontradas no futebol sugere que sua função principal é a descrição e o entendimento das jogadas (cf. "metáforas experienciais" de Heine et al., 1991). Isso não quer dizer que elas não possam ser vistas também como "metáforas expressivas”, que servem para enriquecer a expressividade de uma enunciação. Quando um narrador utiliza a expressão metafórica "chocolate" para descrever algo que poderia ser referido simplesmente como "goleada", sem a utilização de metáfora, é certamente a função expressiva que sobressai. Mas, muitas jogadas não dispõem de uma palavra técnica, de modo que sua descrição se faz primordialmente através do uso das metáforas. É o caso, por exemplo, dos "dribles do chapéu", "do elástico", "da vaca" e assim por diante.

A análise de algumas bases experienciais dessas metáforas mostra que há geralmente semelhanças que podem ser percebidas entre os domínios da experiência que são correlacionados. Em ou- 
PEREIRA, Deize Crespim. As metáforas do futebol brasileiro.

tras palavras, podemos encontrar uma motivação icônica por trás de muitas expressões metafóricas.

Tais expressões comprovam também que os domínios fontes geralmente se referem às nossas experiências mais concretas, ou seja, utilizamos domínios familiares de nossa experiência para conceptualizar o futebol.

É importante ressaltar ainda que as expressões metafóricas encontradas no futebol não implicam ambigüidade. Naquele contexto específico, o sentido focal é o metafórico, e nenhuma das expressões poderia ser tomada literalmente, a não ser para um estrangeiro que desconhecesse nossa cultura.

Lakoff \& Johnson (1980) vêem o futebol como um ritual. Rituais são tipos naturais de atividades para indivíduos ou membros de uma cultura. Os autores propõem que as metáforas culturais são propagadas através dos rituais, e que não há cultura sem ritual. Em nossa visão, o futebol é mais propriamente uma expressão cultural e as metáforas encontradas nas narrações do futebol brasileiro evidenciam isso, ilustrando a maneira específica como nossa sociedade conceptualiza o futebol.

\section{REFERÊNCIAS BIBLIOGRÁFICAS}

BAKHTIN, M. (Voloshinov, 1929) (1979). Marxismo e Filosofia da Linguagem. Trad. M. Lahud e Y.F. Vieira. São Paulo: Huicitec.

CASTILHO, Ataliba T. de (2001). Introdução à Lingüística Cognitiva. Relatório de PósDoutoramento à Fapesp.

CASTILHO, Ataliba T. de (2003). Proposta Funcionalista de Mudança Lingüística: Os Processos de Lexicalização, Semanticização, Discursivização e Gramaticalização na Constituição das Línguas. Relatório de Pós-Doutoramento apresentado ao CNPq.

FERREIRA, Aurélio Buarque de Holanda (1986). Novo Dicionário da Língua Portuguesa. 2. ed. Rio de Janeiro: Nova Fronteira.

GREIMAS, A. J. (1976). Semântica Estrutural: Pesquisa de Método. Trad. H. Osakabe e I. Blikstein. São Paulo: Cultrix/Edusp.

HEINE, Bernd \& CLAUDI, Ulrike \& HÜNNEMEYER, Friederike (1991). Grammaticalization: A Conceptual Framework. Chicago and London: The University of Chicago Press. 
Filol. lingüíst. port., n. 8, p. 113-143, 2006.

LAKOFF, George \& JOHNSON, Mark (1980). Metaphors We Live By. Chicago and London: The University of Chicago Press.

MACHADO, Igor (2005). Entrevista concedida no artigo “A Pátria pendurou as chuteiras?". In: Ciência e Tecnologia no Brasil: Pesquisa Fapesp, novembro 2005, n. 117, p. 90-3.

PRONI, Marcelo Weishaput (2005). Entrevista concedida no artigo "A Pátria pendurou as chuteiras?". In: Ciência e Tecnologia no Brasil: Pesquisa Fapesp, novembro 2005, n. 117, p. 90-93.

TALMY, Leonard (2003). Toward a Cognitive Semantics. Volume 1: Concept Structuring Systems. Cambridge: Massachusetts; London: England, The Mit Press.

ABSTRACT: This paper presents a qualitative analysis of metaphorical expressions found in brazilian soccer domain. The data consist of 316 tokens collected from the speech of brazilian speakers who broadcast soccer games, by radio or television, along the year of 2005. Using the theories of functional linguistics and cognitive linguistics, our goal is to show how we use concrete and familiar domains of our experience to conceptualize the soccer game. The study confirms the existence of iconic, non-arbitrary, motivations that are behind the metaphorical expressions.

KEYWORDS: Metaphors; Brazilian Portuguese; Functional Linguistics; Cognitive Linguistics. 


\title{
A ANTEPOSIÇÃO DOS ADJETIVOS PREDICATIVOS NO PORTUGUÊS CULTO FALADO NO BRASIL*
}

\author{
José da Silva Simões
}

\begin{abstract}
RESUMO: Neste artigo, tratamos da anteposição dos adjetivos no português brasileiro (pb) falado culto na cidade de São Paulo com base nos arquivos do Projeto NURC-SP. O estudo baseia-se na tipologia proposta por Ilari (1990 e 1992) e Castilho (1990) para a categorização dos advérbios em português. O fenômeno da anteposição dos adjetivos foi analisado com o suporte da teoria da variação e levou em conta a análise multiregressiva das variantes anteposição $v s$. posposição de adjetivos. Na primeira parte do texto, traçamos um pequeno histórico a respeito da questão da ordem em pb segundo o estudo de Tarallo (1990). Em seguida, apresentamos uma proposta de tipologização dos adjetivos predicativos em três categorias: quantificadores, aspectualizadores e modalizadores segundo o modelo de Castilho (1992). Na parte final do artigo, discutimos os resultados da análise multiregressiva e do cruzamento dos grupos de fatores estabelecidos para a quantificação dos dados. Na conclusão, reunimos comentários acerca dos fatores que favorecem a anteposição de adjetivos predicativos em $\mathrm{pb}$.
\end{abstract}

PALAVRAS-CHAVE: Português Brasileiro falado; Adjetivos Predicativos; Operadores de Modalização; Gramática Funcional - ordem de palavras.

INTRODUÇÃO

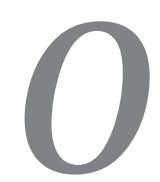

presente trabalho pretende tratar da questão da posição pré e pós-nominal dos adjetivos predicativos na linguagem falada culta de São Paulo. Como base para o estudo dos predicativos, tomamos as considerações a

\footnotetext{
Este artigo é fruto de uma monografia entregue ao Prof. Dr. Ataliba Teixeira de Castilho por ocasião de seu curso A Sintaxe do Adjetivo oferecido em nível de pós-graduação durante o primeiro semestre de 1992 na área de Língua Portuguesa da USP.

" Universidade de São Paulo.
} 
SIMÕES, José da Silva. A anteposição dos adjetivos predicativos no português culto falado...

respeito dos advérbios feitas na Gramática do Português Falado (Castilho,1990 e Ilari, 1992). Fazem parte do corpus de análise as 21 entrevistas transcritas do projeto NURC-SP:

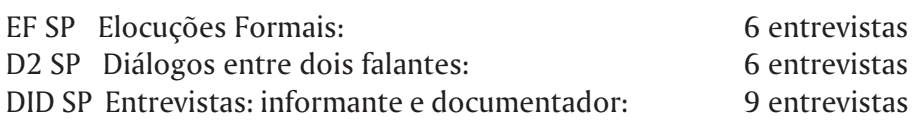

Através de uma abordagem quantitativa dos dados recolhidos nas entrevistas, feita a partir do programa estatístico VARBRUL, procuramos responder as seguintes questões básicas sobre a ordem dos adjetivos predicativos no português falado:

1. Quais os mecanismos que influenciam a escolha do falante para a colocação pré ou pós-nominal dos adjetivos predicativos, uma vez que a questão da ordem dos adjetivos no português contemporâneo apresenta-se predominantemente no esquema NA (Nome + Adjetivo)?

1.1. Que categorias, que tipos de adjetivos predicativos, sobressaem-se na escolha AN (Adjetivo + Nome)?

2. Em que medida a natureza do nome favorece o arranjo AN e/ou NA?

3. Em que medida o lugar do sintagma nominal $(\mathrm{SN})$ e sua fronteira argumental em relação ao verbo influencia na ordem e na escolha de determinadas categorias de adjetivos predicativos?

4. Que elementos influenciam na organização dos SNs ANA (sanduíches adjetivais)?

5. Em que medida a natureza do verbo influencia na escolha e ordem dos Adj predicativos?

6. A dimensão silábica do adjetivo influencia a ordem?

7. A repetição influencia a ordem dos Adj predicativos no SN?

8. A Natureza contável ou não-contável do $\mathrm{N}$ influencia a ordem dos Adj predicativos no SN? 